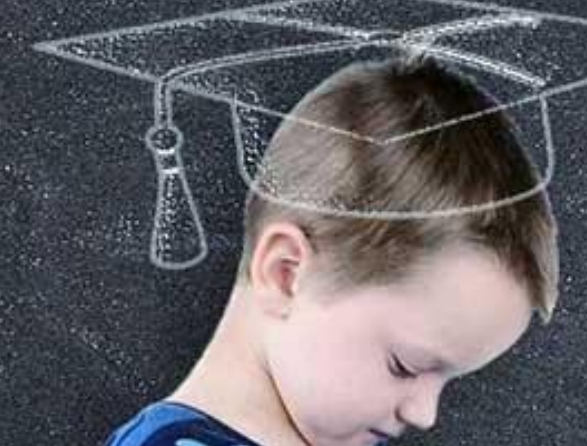

Menghitung Perkembangan Keadaan Pekerja di Indonesia Sumber: Badan Pusat Statistik Agustus 2017 - 2018 menggunakan angka indeks tertimbang dan angka indeks tidak

indeks terti

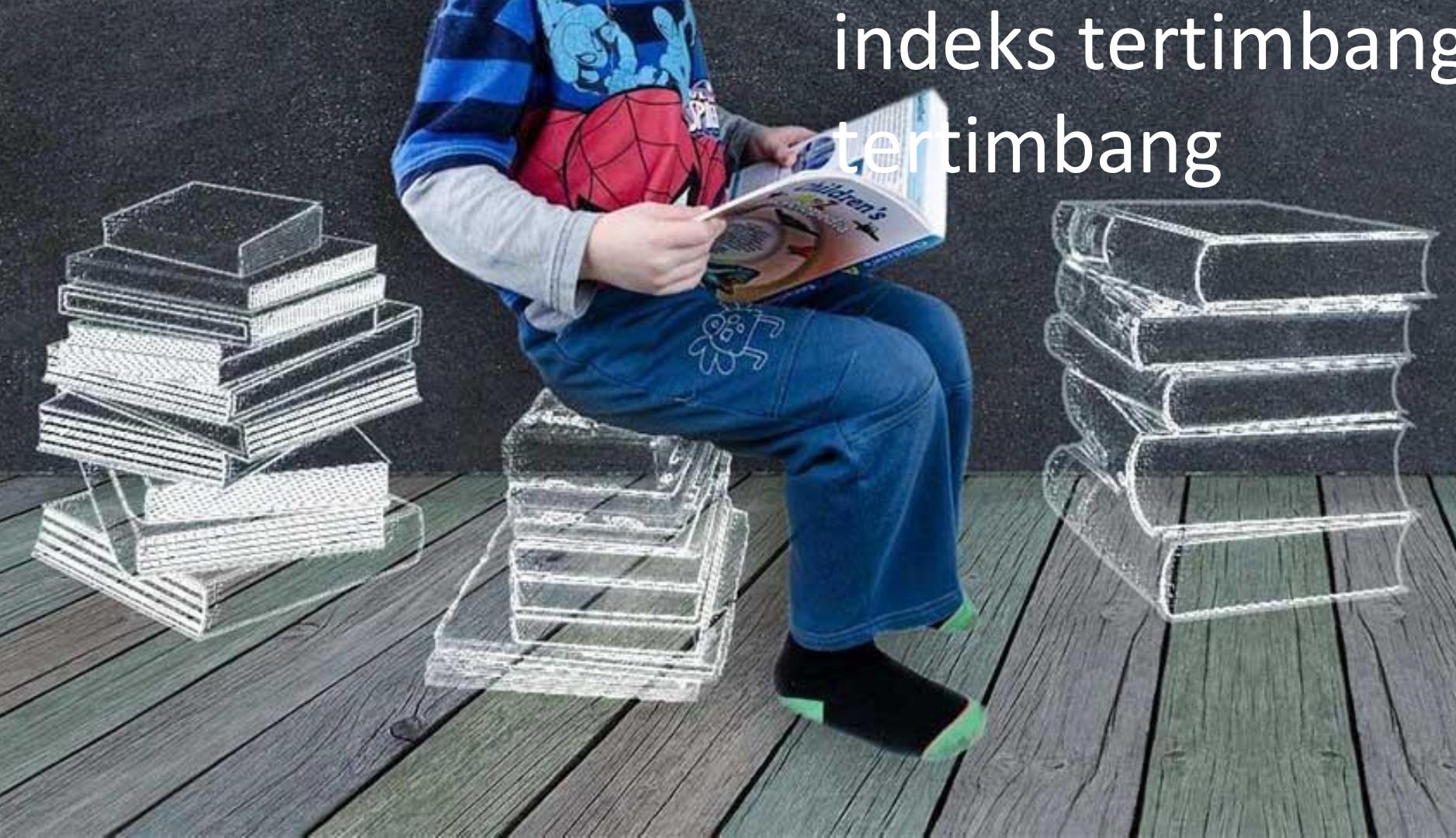

Oleh :

1) Arjun Kusuma Sakti

2) Fadila Raihani

3) Mutia Zaroh 
Añgka indẹks merupakan .. suatu konsep yang dapat memberikan gambaran tentang perubahan-perubahan variabel dari suatu periode ke periode berikutnya. Dengan demikian angka indek dàpat diartikan sebagai angka perbandingan yang perubahan relatifnya dinyatakan dalam bentuk prosentase (\%) terhadap yang lain.

Angka indeks digunakan untuk mengetahui perubahan-perubahan : variabel yang berkaitan dengan banyak aspek kehidupan manusia. Di dalam membuat angka indeks diperlukan dua macam waktu yaitu:

D. waktu dasar (Base period)

$>$ waktu yang bersangkutan/ sedang berjalan (Current period).

Angka indèks juga memiliki dua macem metode perhitungan, yaitu:

$>$ Metode angka indeks tidak tertimbang

$>$ Angka ịndeks tertimbang. 


\section{Angka Indeks Tidak Tertimbang}

Indeks tidak terimbang dalam pembuatannya tidak memasukkan faktor yang mempengaruhi naik-turunnya angka indeks.

Angka indeks tertimbang dibagi menjadi:

A. Indeks Relatif Sederhana (Unweight Index)

B. Indeks Agregat Sederhana
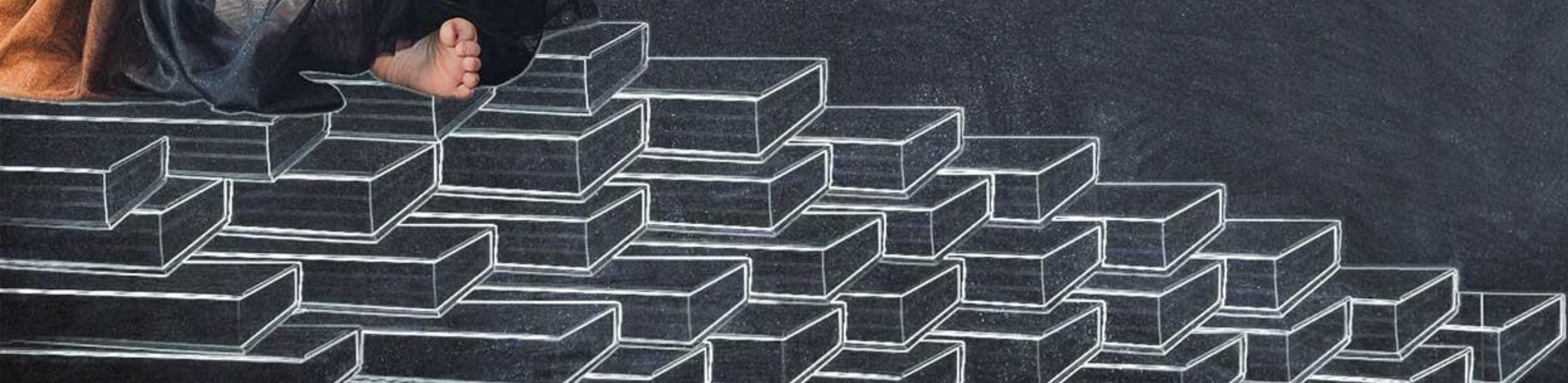


\section{A. Indeks Relatif Sederhana (Unweight Index)}

Indeks relatif sederhana dibagi menjadi empat macam, yaitu:

1. Angka Indeks Harga Relatif Sederhana

2. Angka Indeks Sederhana Relatif Kuantitas

3. Angka Indeks Sederhana Harga Rata - Rata Relatif

4. Angka Indeks Sederhana Kuantitas Rata - Rata Relatif

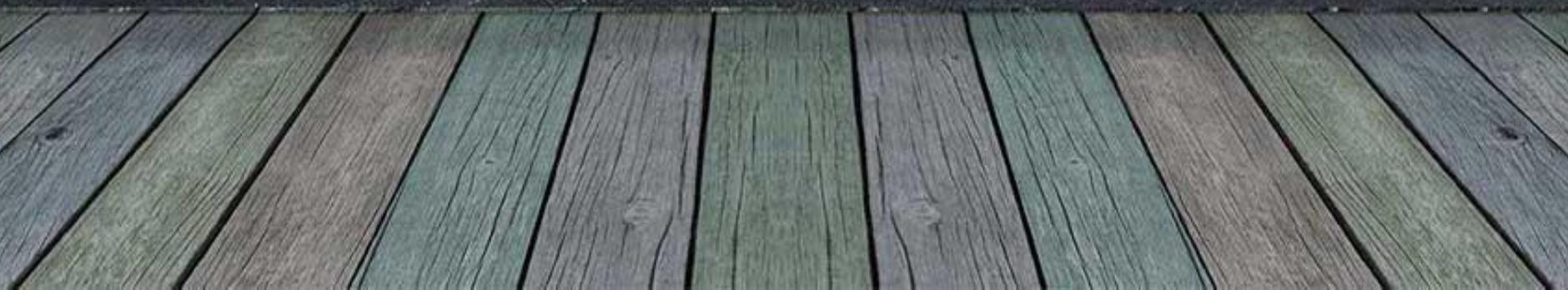




\section{Angka Indeks Harga Relatif Sederhana}

Indeks harga relatif sederhana adalah indeks yang terdiri dari satu macam saja baik untuk indeks produksi maupun harga serta membandingkan suatu harga rlatif suatu barang dan jasa pada tahun berjalan dengan tahun dasar, tanpa memberikan bobot terhadap kepentingan barang dan jasa.

contoh: indeks harga sebuah beras, indeks harga sebuah ayam.

Rumus angka indeks harga relatif sederhana

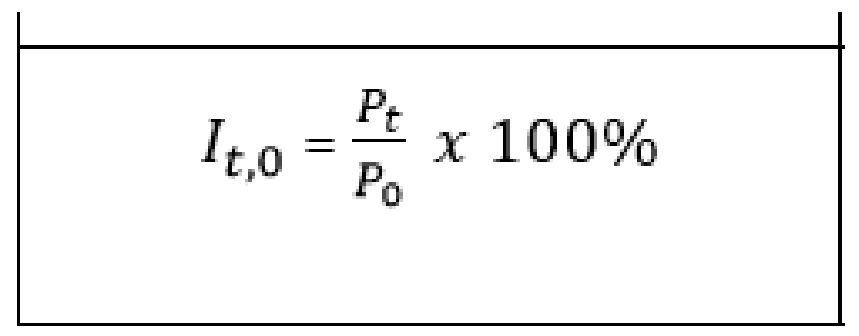

$$
\begin{aligned}
& \text { Keterangan: } \\
& \text { It, } 0=\text { indeks harga pada waktu t dengan } \\
& \text { waktu dasar } 0 \\
& \mathrm{Pt}=\text { harga pada waktu yang ditentukan } \\
& \mathrm{PO}=\text { harga pada waktu tahun dasar }
\end{aligned}
$$




\section{Angka Indeks Sederhana Relatif Kuantitas}

Angka indeks sederhana relatif kuantitas berguna untuk melihat perkembangan kuantitas barang atau jasa dengan tahun lalu atau periode dasar. Angka indeks kuantitas sederhana rlatif kuantitas dihitung tanpa memberikan bobot pada setiap komoditas.

Rumus angka indeks sederhana relatif kuantitas

$$
I_{t, 0}=\frac{Q_{t}}{Q_{0}} \times 100 \%
$$

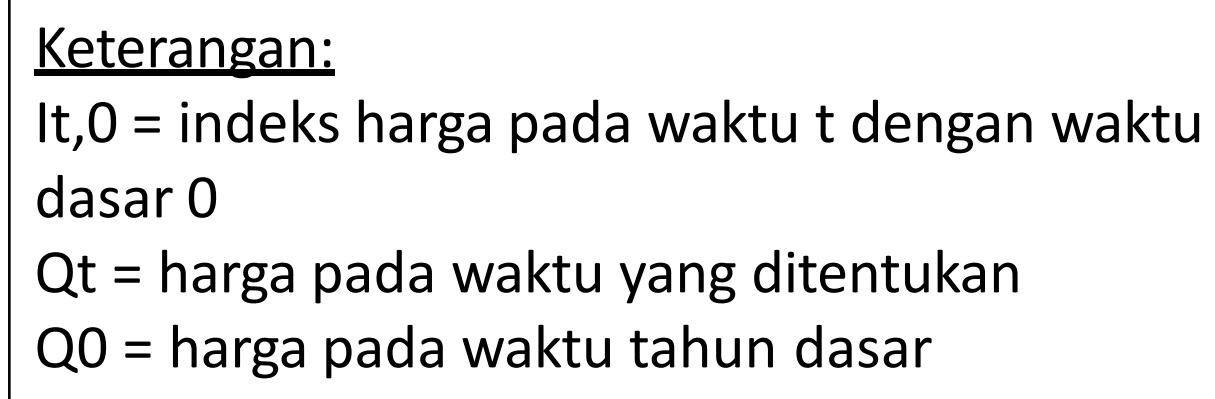




\section{Angka Indeks Sederhana Harga Rata - Rata Relatif}

Angka Indeks Sederhana Harga Rata - Rata Relatif menunjukkan perkembangan nilai harga sauatu baang dan jasa pada suatu periode dengan periode atau tahun dasarnya.

Berikut rumus Angka Indeks Sederhana Harga Rata - Rata Relatif

$I_{R H}=\frac{\sum \frac{P_{t}}{P_{0}} \times 100 \%}{n}$

\section{Keterangan:}

$\mathrm{IRH}=$ Indeks harga pada waktu t dengan waktu dasar 0 $\Sigma \mathrm{Pt}=$ Jumlah harga pada waktu yang ditentukan

$\Sigma \mathrm{PO}=$ Jumlah harga pada waktu tahun dasar

$\mathrm{n}$ = Banyaknya data 


\section{Angka Indeks Sederhana Kuantitas Rata - Rata Relatif}

Angka indeks sederhana kuantitas rata - rata relatif menunjukkan perkembangan nilai kuantitas sauatu baang dan jasa pada suatu periode dengan periode atau tahun dasarnya.

Rumus Angka Indeks Sederhana Kuantitas Rata - Rata Relatif

$$
I_{R H}=\frac{\sum \frac{Q_{t}}{Q_{0}} \times 100 \%}{n}
$$

$\mathrm{IRH}=$ Indeks harga pada waktu t dengan waktu dasar 0

$\Sigma \mathrm{Qt}=$ Jumlah kuantitas pada waktu yang ditentukan

$\Sigma$ Qo = Jumlah kuantitas pada waktu tahun dasar

$\mathrm{n}$ = Banyaknya data 


\section{B. Indeks Agregat Sederhana}

Angka indeks ini menekankan agregasi yaitu barang dan jasa lebih dari satu . Harga, kuantitas, dan nilai dijadikan satu, sehingga mendapatkan angka indeks yang mewakili agregasi tersebut.

Indeks Agregat Sederhana Ini dibagi menjadi dua macam, yaitu:

1. Angka Indeks Sederhana Harga Agregatif

2. Angka Indeks Sederhana Kuantitas Agregatif

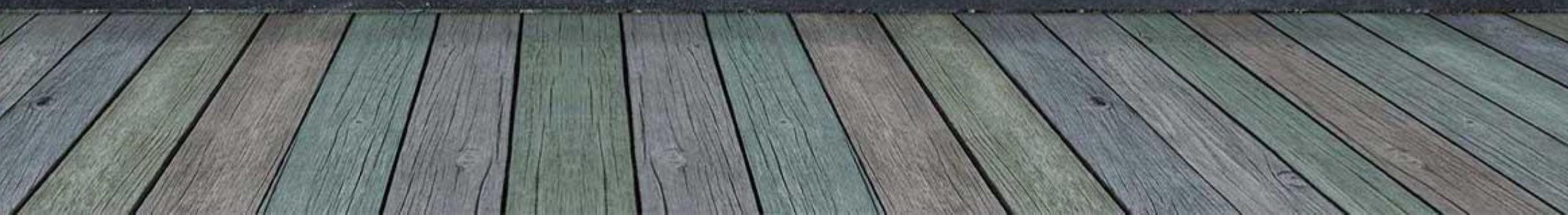




\section{Angka Indeks Sederhana Harga Agregatif}

Angka indeks sederhana harga agregatif adalah angka indeks yang berfungsi untuk membandingkan antara jumah harga barang dan jasa pada periode tertentu dengan periode dasarnya.

Rumus Angka Indeks Sederhana Harga Agregatif

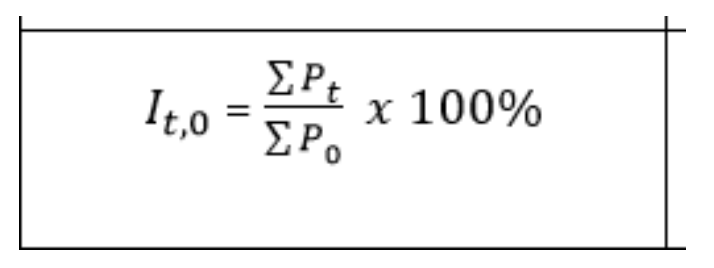

Keterangan:

It0 = Indeks harga pada waktu t dengan waktu dasar 0

$\Sigma \mathrm{Pt}=$ Jumlah harga pada waktu yang ditentukan

$\Sigma \mathrm{PO}=$ Jumlah harga pada waktu tahun dasar 


\section{Angka Indeks Sederhana Kuantitas Agregatif}

Angka indeks sederhana kuantitas agregatif adalah angka indeks yang berfungsi untuk membandingkan antara jumah kuantitas barang dan jasa pada periode tertentu dengan periode dasarnya.

Rumus angka indeks sederhana kuantitas agregatif

$$
I_{t, 0}=\frac{\sum Q_{t}}{\sum Q_{0}} \times 100 \%
$$$$
\text { Keterangan: }
$$$$
\text { It0 }=\text { Indeks harga pada waktu t dengan waktu }
$$$$
\text { dasar } 0
$$$$
\Sigma Q t=\text { Jumlah kuantitas pada waktu yang }
$$$$
\text { ditentukan }
$$$$
\Sigma Q 0=\text { Jumlah kuantitas pada waktu tahun dasar }
$$ 


\section{A. Harga Agregatif Tertimbang}

Indeks ini dibagi menjadi dua bagian, yaitu:

\section{Indeks Laspeyres}

Indeks ini dikembangkan pada abad ke-18 oleh Etienne Laspeyres. Indeks ini menggunakan kuantitas periode dasar sebagai pembobot.

Rumus indeks Laspeyres

$$
L_{H}=\frac{\sum\left(P_{t} \cdot Q_{0}\right)}{\sum\left(P_{0} \cdot Q_{0}\right)} \times 100 \%
$$

Keterangan:

$\mathrm{LH}=$ Indeks laspeyres harga

$\Sigma$ Pt.QO = Penjumlahan harga periode tetentu dikali kuantitas periode dasar $\Sigma$ PO.QO = Penjumlahan harga periode dasar dikali kauntitas periode dasar

\section{Indeks Paasche}

Indeks ini menggunakan kuantitas tahun ke-n, sebagai faktor penimbang. Berikut rumus dari indeks Paasche:

Rumus Indeks Paasche

$$
P_{H}=\frac{\sum\left(P_{t} \cdot Q_{t}\right)}{\sum\left(P_{0} \cdot Q_{t}\right)} \times 100 \%
$$

\section{Keterangan:}

$\mathrm{PH}=$ Indeks Paasche harga $\Sigma$ Pt.Qt $=$ Penjumlahan harga periode tetentu dikali kuantitas periode tertentu $\Sigma$ P0.Qt $=$ Penjumlahan harga periode dasar dikali kauntitas periode tertentu. 


\section{B. Indeks Produk Agregatif Tertimbang}

Indeks ini dibagi menjadi dua bagian, yaitu:

\section{Indeks Laspeyres}

Indeks ini menggunakan harga periode dasar sebagai pembobot. Berikut rumus dari indeks laspeyres:

Rumus indeks laspeyres:

$$
L_{P}=\frac{\sum\left(P_{0} . Q_{t}\right)}{N}
$$

\section{Keterangan:}

$\mathrm{LP}=$ Indeks laspeyres produk

$\Sigma P 0 . Q t=$ Penjumlahan harga periode dasar dikali kuantitas periode tertentu

$\Sigma$ PO.QO = Penjumlahan harga periode dasar dikali

kauntitas periode dasar

\section{Indeks Paasche}

Indeks ini menggunakan harga tahun ke-n, sebagai faktor penimbang.

Rumus Indeks Paasche

$$
P_{P}=\frac{\sum\left(P_{t} \cdot Q_{t}\right)}{\sum\left(P_{t} \cdot Q_{0}\right)} \times 100 \%
$$

Keterangan:

$\mathrm{PP}=$ Indeks Paasche produk

$\Sigma$ Pt.Qt $=$ Penjumlahan harga periode tetentu dikali kuantitas periode tertentu

$\Sigma$ Pt.Q0 = Penjumlahan harga periode tertentu dikali kauntitas periode dasar. 


\section{Variasi dari Indeks Tertimbang}

Indeks ini dibagi menjadi dua bagian, yaitu:

\section{Indeks Fischer}

Indeks ini adalah pengakaran dari kedua indeks laspeyres

dan indeks paasche.

$$
\begin{gathered}
\begin{array}{c}
\text { Rumus indeks fischer untuk } \\
\text { harga tertimbang }
\end{array} \\
F_{H}=\sqrt{L_{H} x P_{H}}
\end{gathered}
$$$$
\begin{array}{|c|}
\hline \begin{array}{c}
\text { Rumus indeks fischer untuk } \\
\text { produk tertimbang }
\end{array} \\
\hline F_{P}=\sqrt{L_{P} x P_{P}} \\
\hline
\end{array}
$$

Keterangan:

$\mathrm{FH} / \mathrm{HP}=$ Variasi harga/produk indeks tertimbang

$\mathrm{LH} / \mathrm{LP}=$ Laspeyres harga/pruduk $\mathrm{PH} / \mathrm{PP}=$ Paasche

harga/produk

\section{Indeks Drobisch}

Indeks ini digunakan apabila nilai indeks berbeda jauh. Indeks

ini merupakan rata - rata dari indeks laspeyres dan indeks paasche.
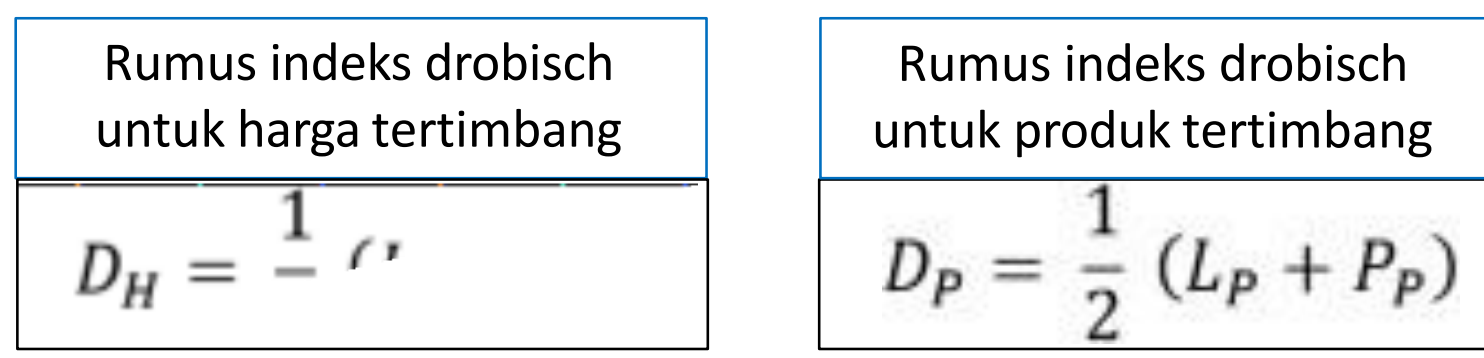

\section{Keterangan:}

$\mathrm{DH} / \mathrm{DP}=$ Drobisch harga/produk

LH/LP = Laspeyres harga/produk

$\mathrm{PH} / \mathrm{PP}=$ Paasche harga/produk 
Menghitung Perkembangan Keadaan Pekerja di

berdasarkan Badan Pusat Statistik Agustus 2017 - 2018

menggunakan aplikasi Excel dan secara manual

\begin{tabular}{|c|r|r|r|r|}
\hline \multirow{2}{*}{ STATUS PEKERJAAN UTAMA } & \multicolumn{3}{|c|}{ TAHUN } \\
\cline { 2 - 5 } & \multicolumn{2}{|c|}{ AGUSTUS 2017 } & \multicolumn{2}{|c|}{ AGUSTUS 2018 } \\
\cline { 2 - 5 } & \multirow{2}{*}{ JUMLAH PEKERJA } & PENDAPATAN BERSIH & \multirow{2}{*}{ JUMLAH PEKERJA } & PENDAPATAN BERSIH \\
\hline BURUH/ KARYAWAN/ PEGAWAI & $48,047.068$ & $2,742.621$ & $49,231.568$ & \\
\hline PEKERJA BEBAS DI PERTANIAN & $5,848.256$ & $1,018.447$ & $5,205.794$ & $2,829.130$ \\
\hline PEKERJA BEBAS DI NONPERTANIAN & $7,158.103$ & $1,591.468$ & $6,973.409$ & $1,103.093$ \\
\hline JUMLAH & $61,053.427$ & $5,352.536$ & $61,410.771$ & $1,700.936$ \\
\hline
\end{tabular}

\section{a. Menghitung Angka Indeks Tertimbang dan Tidak Tertimbang menggunakan Excel}

1) Angka Indeks Tidak Tertimbang

1. Aktifkan program Microsoft Excel hingga terdapat worksheet kosong

2. Masukkan rumus $=$ kolom/kolom $* 100 \%$ untuk menghitung harga dikalikan kuantitas begitupun sebaliknya 
1. Masukkan rumus $=$ kolom $/$ kolom $* 100 \%$, ini sesuai penempatan data yang dibuat, rumus ini untuk mencari semua angka indeks tidak tertimbang, kecuali untuk mencari rata - rata relatif menggunakan rumus $=1 / \mathrm{n} *$ (data penempatan penjumlahan harga dibagi kuantitas)

2) Angka Indeks Tertimbang

1. Aktifkan program Microsoft Excel hingga terdapat worksheet kosong

2. Masukkan rumus =kolom*kolom untuk menghitung harga dikalikan kuantitas begitupun sebaliknya

3. Masukkan rumus $=$ kolom/kolom (ini sesuai data penempatannya) $* 100 \%$, rumus ini digunakan untuk indeks Laspeyres dan indeks Paasche

4. Masukkan rumus =SQRT(kolom*kolom(ini sesuai penempatan datanya) $)$ ini digunakan untuk mencari indeks Fischer

5. Masukkan rumus $=1 / 2($ kolom*kolom(ini sesuai data penempatannya) rumus ini digunakan untuk mencari indeks Drobisch 


\section{Menghitung Angka Indeks Tertimbang dan Tidak Tertimbang secara manual}

\begin{tabular}{|c|c|c|c|c|}
\hline \multirow{3}{*}{ STATUS PEKERJAAN UTAMA } & \multicolumn{4}{|c|}{ TAHUN } \\
\hline & \multicolumn{2}{|c|}{ AGUSTUS 2017} & \multicolumn{2}{|c|}{ AGUSTUS 2018} \\
\hline & JUMLAH PEKERJA & PENDAPATAN BERSIH & JUMLAH PEKERJA & PENDAPATAN BERSIH \\
\hline BURUH/ KaRYAWAN/PEGAWAI & $48,047,068$ & $2,742,621$ & $49,231.568$ & $2,829.130$ \\
\hline
\end{tabular}

\begin{tabular}{|c|c|c|c|c|}
\hline \multirow{3}{*}{ STATUS PEKERJAAN UTAMA } & \multicolumn{4}{|c|}{ TAHUN } \\
\hline & \multicolumn{2}{|c|}{ AGUSTUS 2017} & \multicolumn{2}{|c|}{ AGUSTUS 2018} \\
\hline & JUMLAH PEKERJA & PENDAPATAN BERSIH & JUMLAH PEKERJA & PENDAPATAN BERSIH \\
\hline BURUH/KARYAWAN/ PEGAWAI & $48,047.068$ & $2,742,621$ & $49,231.568$ & $2,829.130$ \\
\hline PEKERJA BEBAS DI PERTANIAN & $5,848.256$ & $1,018.447$ & $5,205.794$ & $1,103.093$ \\
\hline PEKERJA BEBAS DI NONPERTANIAN & $7,158,103$ & $1,5991,468$ & $6,973.409$ & $1,700.936$ \\
\hline JUMLAH & $61,053.427$ & $5,352.536$ & $61,410,771$ & $5,633.159$ \\
\hline
\end{tabular}

\section{Angka Indeks Tidak Tertimbang}

a. Indeks Relatif Sederhana ( Unweight Index)

1) Angka Indeks Harga Relatif SederhanaIt, $0=\frac{P t}{P 0} x 100 \%$

$$
=\frac{2.829 .130}{2.742 .621} \times 100 \%
$$

$$
=1.0315 \%
$$

2) Angka Indeks Sederhana Relatif Kuantitas

$$
\begin{gathered}
I t, 0=\frac{Q t}{Q 0 x} 100 \% \\
=\frac{49.231 .568}{48.047 .068 \times 100} \%
\end{gathered}
$$$$
=102 \%
$$

3) Angka indeks sederhana harga rata - rata

$$
\begin{gathered}
I t, 0=\frac{1}{n} \frac{\sum P t}{P 0} 100 \% \\
=\frac{1}{6} 1.0524 \% \\
=17.54
\end{gathered}
$$

4) Angka indeks sederhana kuantitas rata - rata

$$
I t, 0=\frac{i}{n} \frac{\sum Q t}{Q 0}=100 \%
$$


a. Indeks Agregat Sederhana

1) Angka Indeks Sederhana Harga Agregatif

$$
\begin{aligned}
I t, 0 & =\frac{\sum P t}{\sum P 0} 100 \% \\
& =\frac{5.633 .159}{5.352 .536} \times 100 \% \\
& =10.524 \%
\end{aligned}
$$

2) Angka Indeks Sederhana Kuantitas Agregatif

$$
\begin{aligned}
\text { It, } 0 & =\frac{\sum Q t}{\sum Q 0} 100 \% \\
& =\frac{49.231 .568}{48.047 .068} \times 100 \% \\
& =10.059 \%
\end{aligned}
$$

a. Indeks Harga Agregatif Tertimbang

1) Indeks Laspeyres

$$
\begin{array}{r}
L H=\frac{\sum P t Q 0}{\sum P 0 Q 0} \times 100 \% \\
=\frac{154.558 .046 .83}{149.122 .928 .34} \times 100 \% \\
=10.364 \% \\
L P=\frac{\sum P 0 Q t}{\sum P 0 Q 0} \times 100 \% \\
=\frac{151.423 .314 .81}{149.122 .928 .34} \times 100 \% \\
=10.154 \%
\end{array}
$$

2) Indeks Paasche

$$
\begin{array}{r}
P H=\frac{\sum P t Q t}{\sum P 0 Q t} \times 100 \% \\
=\frac{156.886 .303 .31}{151.423 .314 .81} \times 100 \% \\
=10.361 \%
\end{array}
$$




$$
\begin{gathered}
P P=\frac{\sum P t Q t}{\sum P t Q 0} \times 100 \% \\
=\frac{156.886 .303 .31}{154.558 .046 .83} \times 100 \% \\
=10.151 \%
\end{gathered}
$$

2) Indeks Drobisch

a. Variasi dari Indeks Tertimbang

$$
I H=\frac{1}{2}(L+P)
$$

1) Indeks Fischer

$$
\begin{gathered}
=\frac{1}{2}(10.364 \%+10.361 \%) \\
=103.63
\end{gathered}
$$

$=\sqrt{10.364} \% \times 10.361 \%$

$$
=103.62
$$

$$
I P=\frac{1}{2}(L+P)
$$

$$
\begin{aligned}
& I P=\sqrt{L} x P \\
& =\sqrt{10.154} \% \times 10.151 \% \\
& =101.52
\end{aligned}
$$$$
=\frac{1}{2}(10.154 \%+10.151 \%)
$$$$
=101.53
$$ 


\section{Kesimpulan}

Dari pembahsan diatas kita dapat menyimpulkan bhwa angka indeks memiliki dua metode perhitungan yaitu: Angka Indeks Tidak Tertimbang dan Angka Indeks Tertimbang, dari metode - metode ini dibagi lagi menjadi beberapa macam, ada yang mempertimbangkan suatu bobot dan ada juga yang mempertimbangkannya. Dari perhitungan menggunakan excel maupun secara manual hasil nya sama. 


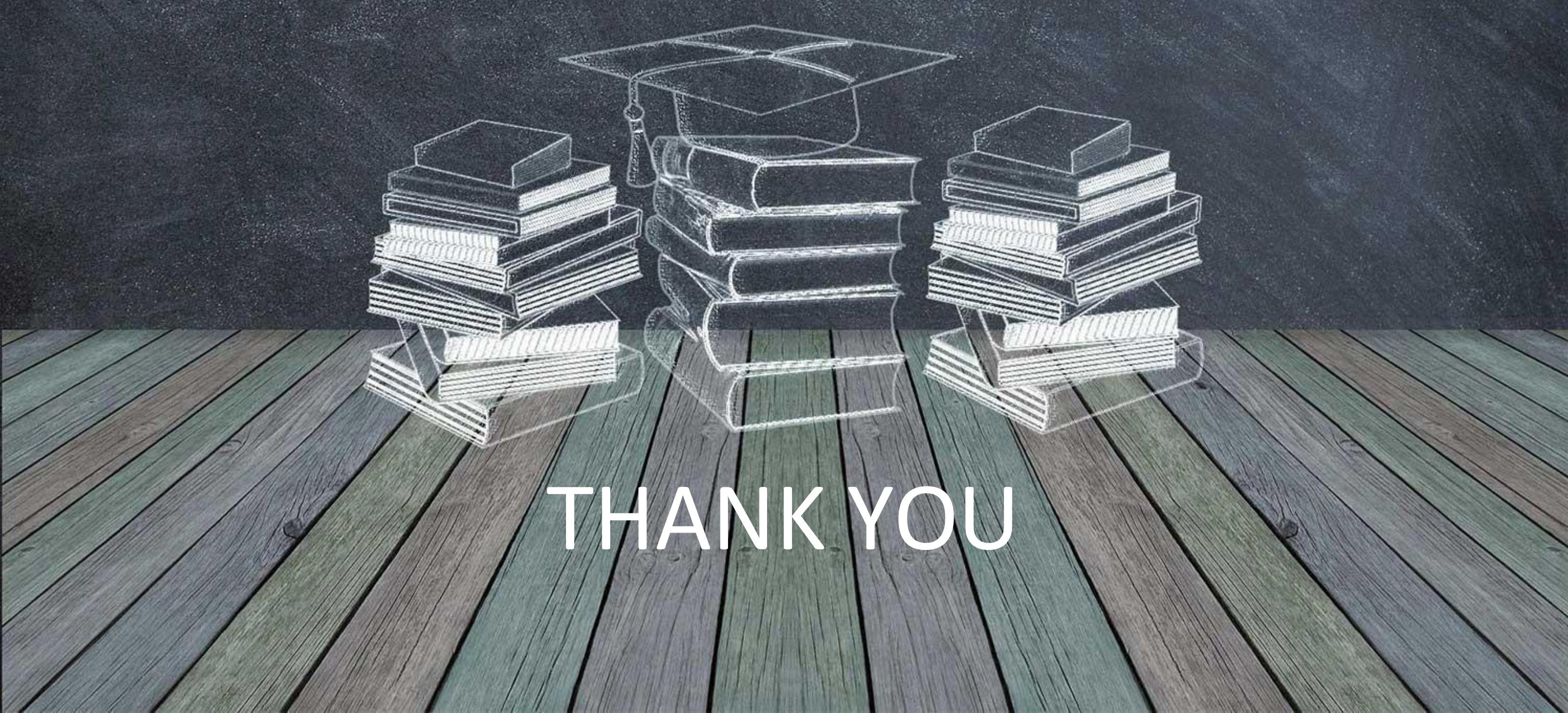

